\title{
The Effect of Information Frame and Motivation Attribution on the Green Consumption Behavior of Hotel Consumers
}

\author{
Jiajing $\mathrm{HU}^{*}$ \\ School of tourism management \\ Sichuan Agricultural University \\ Dujiangyan, China \\ jiajing111@sina.com
}

\author{
Lin XIONG \\ School of tourism management \\ Sichuan Agricultural University \\ Dujiangyan, China \\ linlin_x@foxmail.com
}

\author{
Qiu WAN \\ School of tourism management \\ Sichuan Agricultural University \\ Dujiangyan, China \\ 1623030072@qq.com
}

\begin{abstract}
Taking college students as experimental objects and selecting the green consumption of "quilt cover laundering" in the hotel as the research scenario, this study discusses the effect of information frame and motivation attribution on the green consumption behavior of hotel consumers by the scenario experiment of 3 (Gain frame/ loss frame / nonframe) $\times 2$ (selfinterest attribution / altruism attribution). The results show that the framing effect exists extensively in the hotel green consumption scenario, and the loss frame can promote the green consumption behaviors of the hotel consumers better than the gain frame. Moreover, the loss frame can promote the green consumption behaviors of the hotel consumers better than gain frame when the hotel consumers make the altruistic attribution to the corporate motives. However, when hotel consumers make the self-interest attribution to corporate motives, there is no significant difference between the loss framing effect and gain framing effect, and it is hard for them to promote consumers' green consumption behavior intentions. This study will help hotels guide consumers to implement green consumption
\end{abstract}

Keywords-gain frame; loss frame; motivation attribution; hotel green consumption behavior

\section{INTRODUCTION}

The phenomenon of resource waste exists extensively in the hotels, which are the high consumption places in tourism industry. In order to realize energy conservation and emission reduction, on one hand, hotels are striving to develop green ones; on the other hand, they are conducting green consumption of consumers. Tourists' knowledge and attitude toward hotel green environmental protection can directly affect the effectiveness of hotels' environment management. Therefore, how to effectively promote the green consumption service has become a matter of concern for hotels.

This study was supported by grants from. Tourism Bureau of Sichuan Province(No: SCTYETP2016L31)

\section{Literature Review AND Hypothesis Proposition}

\section{A. Definition and Types of Information Frame}

The information frame is a kind of representation of information. Kahnenam and Tversky found that changes in the information frame can lead to different decisions for individuals on the selecting plans of the same problem ${ }^{[1]}$. Levin et al. divided framing effects into three different types, namely risk framing effect, attribute framing effect and goal framing effect. The risk framing effect refers to the fact that for the same information, the individual would tend to choose the risk-free option when facing the gain frame, while the risk option when facing the loss frame. The attribute framing effect refers to the phenomenon that compared with negative frame, people prefer to use the positive frame to describe the key features of something. Levin et al. also believed that language strategies to express behavioral goals could affect the influence of persuasive information. Then this phenomenon was called the goal framing effect. Besides, according to the different expression ways, it is divided into the gain frame and loss frame. The gain frame emphasizes the benefits of doing something, and the loss frame emphasizes the consequences of not doing something ${ }^{[2]}$.

\section{B. Goal Frame and Consumption Decision}

The goal frame is mainly used to describe the result or goal of the behavior, which will affect the persuasiveness of the information. Therefore, this study selects the goal frame as the research object. Compared with the neutral information presentation, the goal frame can improve the persuasiveness of information ${ }^{[2]}$, that is whether the use of the goal information frame will affect the decision-making. In the charity donation advertisements, Chang and Lee believed that the loss frame was more persuasive than the gain framing ${ }^{[3]}$. In the purchase behaviors, Li Dongjin also proved that the loss frame was 
more conducive to consumers' willingness to buy virtual products than to the gain frame ${ }^{[4]}$. The view of prospect theory holds that people have negative biases when dealing with information. Therefore, people are more sensitive to "loss" than "gain" when facing the same benefits. Thus, the first hypothesis is:

$\mathrm{H}_{1 \mathrm{a}}$ : Compared with not using the goal frame, using the goal frame can promote the green consumption behaviors of hotel consumers.

$\mathrm{H}_{1 \mathrm{~b}}$ : Compared with the gain frame, the loss frame can promote the green consumption behavior of hotel consumers.

\section{Moderating Effect of Motivation Attribution}

Heider thought that people would explain the cause of an action or event that has already taken place based on various clues, and this explanation process was called the attribution ${ }^{[5]}$ When consumers saw that corporates performed social responsibilities through pro-social activities, Kou Yan divided consumers' motivation attributions about the corporates into two types, namely, self-interest and altruistic attribution ${ }^{[6]}$. According to the existing literature, this study divides corporate motivations into two categories: (1) altruistic motivation, such as promoting the development of social environmental protection sincerely and implementing social responsibilities of enterprises actually; (2) self-interest motivation, such as increasing profits, saving costs, promoting sales or enhancing brand image.

Consumers' attribution of corporate prosocial behaviors will affect their subsequent behaviors and attitudes ${ }^{[6]}$. When consumers make altruistic attributions, they will have a positive impact on corporate social responsibility behaviors ${ }^{[7]}$. However, when consumers regard corporate social responsibility as a marketing tool to promote sales, consumers will resist the purchases ${ }^{[8]}$. Thus, we put forward the second hypothesis:

$\mathrm{H}_{2}$ : Compared with self-interest attribution, hotel consumers have stronger green consumption behaviors when they make the altruism attribution for hotel motivations.

Furthermore, we speculate that the attribution will moderate the role of the goal frame. Since consumers are not quite sure that whether corporates are motivated by the selfinterest or altruistic motivation, in this study, we believe that the altruistic motivation of a corporate is stronger when the altruistic attribution of the individual is higher than the selfinterest attribution. Besides, in the field of consumer behavior, because the negative information is more diagnostic than the positive information, we believe that a corporate's self-interest motivation is stronger when the individual's self-interest attribution to the corporate is greater than or equal to altruistic attribution. Thus, we propose the third hypothesis:

$\mathrm{H}_{3 \mathrm{a}}$ : When hotel consumers make the altruistic attribution to corporate motives, the loss frame will lead to more active green consumption behaviors than the gain frame.

$\mathrm{H}_{3 \mathrm{~b}}$ : When hotel consumers make self-interest attribution to corporate motives, there is no significant difference between the two frames, and they will not promote consumers' green consumption behaviors.

\section{RESEARCH DESIGN}

\section{A. Stimulus Materials in Experiment}

This study uses the scenario simulation experiment designed to capture the effect of different goal information frames on hotel consumers' green behaviors through a set of 3 (gain frame/loss frame/frameless) * 2 (self-interest attribution/ altruistic attribution) scenarios. Then, this study selects the scenario of "reminding consumers to reduce the times of laundering sheets and quilt covers" as an experiment stimulus. According to Levin's research $\left[{ }^{2]}\right.$, the goal information frame is divided into two types: the loss frame and the gain frame. Specifically, the loss frame describes the consequences of not being able to reduce the times of laundering, the gain frame describes the benefits that can be achieved when the covers are changed less, and the frameless is used as a control group, which is non-information frame, and is only used to the simple reminding.

\section{B. Participants in Experiment}

This study selects college students as experiment objects, which is mainly based on the following reasons: (1) College students have a high level of education, the new knowledge structure, and a strong curiosity. So, they are more likely to try the green consumption. (2) College students are potential consumers for hotels. (3) For the current age, college students will be the main body of the green consumption in the next ten or decades. Therefore, it is necessary to understand the views and attitudes of college students on green consumption behaviors.

\section{Measurements of Variables}

The dependent variable in the experiment is the intention to of a participant' green consumption behavior. The items are "I will do less to change and launder sheets and quilt covers when I see this kind tip”, “ I'm going to call on my peers to do less to change and launder sheets and quilt covers when I see this kind tip", and "I will advertise reducing the laundering of sheets and quilt covers to others when I see this kind tip”.

The moderating variable in the experiment is the motivation attribution. Using Ellen's scales, firstly, the terms of self-interest attribution are designed to: (1) "When I see this kind tip, I think that the hotel is to establish the green and environmentally-friendly image". (2) "When I see this kind tip, I think the hotel is to save costs". Secondly, the terms of altruistic attribution are designed to: (1) When I see this kind tip, I think the hotel is actually fulfilling its social responsibilities". (2) "When I see this kind tip, I think the hotel is sincerely promoting the development of social environmental protection”.

The above variables are tested by Likert's 7-point scale, and the answers are divided into 7 expressions including "completely disagree”, "strongly disagree”, "moderately disagree”, "neither agree nor disagree”, "moderately agree”, "strongly agree” and "completely agree”. 


\section{Statistical Analysis Result}

\section{A. Basic Characteristics of Participants}

There are 122 questionnaires collected in the experiment, including 40 in the loss scenario, 42 in the frameless scenario, and 40 in the gain scenario. According to the statistical analysis of demographic characteristics, male participants account for $18 \%$ of the total number of samples, and females account for 82\%; 18 years old or younger participants account for $27.9 \%$, and 19 to 35 years old participants account for $72.1 \%$.

In terms of the "green consumption behavior" of consumers different genders, the variance of the two groups is homogenous, $t=1.512, d f=120, P=0.133>0.05$, which does not reach the significant level. Hence, the analysis results show that the green consumption behavior will not be significantly different due to the gender.

Besides, in terms of the "green consumption behavior" of consumers of different ages, the variance of the two groups is homogenous, $t=-1.698, d f=120, P=0.092>0.05$, which does not reach the significant level. Therefore, the analysis results show that the green consumption behavior will not be significantly different due to the age.

\section{B. Reliability Analysis}

The Cronbach's alpha of the scale is 0.761 , indicating that the internal consistency of the scale is good, and the data collected by the questionnaire has the high reliability.

\section{Hypothesis Testing}

1) Verification of the Effect of the Goal Information Frame on Green Consumption Behavior

TABLE I shows that there are significant differences in the effect of green consumption behavior intentions of participants under the three scenarios of frameless, loss frame, and gain frame $\left(M_{\text {loss }}=4.1905, M_{\text {gain }}=3.5333, M_{\text {frameless }}=2.9167 ; F\right.$ $(2,119)=8.645, P<0.0001)$. The LSD test has found that, firstly, the difference value between the "loss frame" group and "frameless" group in mean value of green consumption behavior intention is 1.27381, $P<0.0001$. Secondly, the difference value between the "gain frame" and "frameless" groups in mean value of green consumption behavior intention is $0.61667, P=0.049<0.05$. Thirdly, the difference value between the "loss frame" group and the "gain frame" group in mean value of green consumption behavior intention is $0.65714, P=0.034<0.05$. Therefore, the data shows that the use of the goal frame can promote consumers' green consumption behaviors more than the non-use of the goal frame, and the loss frame can promote participants' green consumption behaviors more effectively. Thus, $\mathrm{H}_{1 \mathrm{a}}$ and $\mathrm{H}_{1 \mathrm{~b}}$ are statistically accepted.

TABLE I. THE RESULTS OF ANOVA UNDER DIFFERENT FRAMES

\begin{tabular}{|c|c|c|c|c|}
\hline Test variable & Frame & $\mathrm{N}$ & Mean value & F-test \\
\hline \multirow{2}{*}{$\begin{array}{c}\text { Green } \\
\text { consumption } \\
\text { behavior } \\
\text { intention }\end{array}$} & Loss frame & 42 & 4.1905 & \multirow{2}{*}{$8.645^{* * *}$} \\
\cline { 2 - 4 } & Gain frame & 40 & 3.5333 & \\
\cline { 2 - 4 } & Frameless & 40 & 2.9167 & \\
\hline
\end{tabular}

Note: ${ }^{* * *} p<0.0001$
2) Verification of the Effect of Motivation Attribution on Green Consumer Behavior

TABLE II shows that there are significant differences of green consumption behaviors between different motivation attributions $\left(M_{\text {altruism }}=4.1304, M_{\text {selfinterest }}=3.2105 ; F(1,120)\right.$ $=12.223, P=0.001)$, which means that when making the altruism attribution for hotels' motivations, consumers are more willing to implement green consumption behaviors. Thus, $\mathrm{H}_{2}$ is supported.

TABLE II. THE RESULTS OF ANOVA UNDER DIFFERENT ATTRIBUTIONS

\begin{tabular}{|c|c|c|c|c|}
\hline Test variable & Motivation attribution & $\mathrm{N}$ & Mean value & F-test \\
\hline $\begin{array}{c}\text { Green } \\
\text { consumption } \\
\text { behavior } \\
\text { intention }\end{array}$ & Altruism attribution & 46 & 4.1304 & \multirow{2}{*}{$12.223^{*}$} \\
\cline { 2 - 4 } & $\begin{array}{c}\text { Self-interest } \\
\text { attribution }\end{array}$ & 76 & 3.2105 & \\
\hline
\end{tabular}

Note: ${ }^{*} p<0.05$

3) Verification of the Moderating Effect of Motivation Attribution on the Frame

TABLE III shows that when the hotel consumers make the altruistic attribution to the hotel's kind tip, frame strategies have a significant effect on the green consumption behaviors of participants $\left(M_{\text {loss }}=5.1481, M_{\text {gain }}=3.5952, M_{\text {frameless }}\right.$ $=3.3571 ; F(2,43)=9.045, P=0.001)$. The LSD test has found that, the difference value between the "loss frame" group and the "gain frame" group in mean value of green consumption behavior intention is 1.55291 , and $P=0.002<0.05$, and the difference value between the "loss frame" group and the "frameless" group in mean value of green consumption behavior intention is $1.79111, P<0.001$. These results indicate that if the hotel's altruistic motivation is stronger, using the loss frame can be a better incentive for consumers to engage in green consumer behaviors. Thus, $\mathrm{H}_{3 \mathrm{a}}$ is supported.

TABLE IV shows that when the hotel consumers make the self-interest attribution to the hotel's kind tip, frame strategies have a significant effect on the green consumption behaviors of participants $\left(M_{\text {loss }}=3.4722, M_{\text {gain }}=3.5000, M\right.$ frameless $=2.6795 ; F(2,73)=3.333, P=0.041)$. The LSD test has found that, the difference value between the "loss frame" group and the "gain frame" group in mean value of green consumption behavior intention is $-0.02778, P=0.094>0.05$. That is, there is no significant difference in the green consumption behavior intention between the "loss frame" group and the "gain frame" group, and their values of behavior intention are less than 4, which cannot promote consumers' green consumer behaviors. Thus, $\mathrm{H}_{3 \mathrm{~b}}$ is supported.

TABLE III. THE RESULTS OF ANOVA UNDER ALTRUISTIC ATTRIBUTION

\begin{tabular}{|c|l|c|c|c|}
\hline Test variable & \multicolumn{1}{|c|}{ Frame } & $\mathrm{N}$ & Mean value & F-test \\
\hline \multirow{2}{*}{$\begin{array}{c}\text { Green } \\
\text { consumption } \\
\text { behavior } \\
\text { intention }\end{array}$} & Loss framing & 18 & 5.1481 & \\
\cline { 2 - 4 } & Gain framing & 14 & 3.5952 & \multirow{2}{*}{$9.045^{*}$} \\
\cline { 2 - 4 } & Frameless & 14 & 3.3571 & \\
\hline
\end{tabular}

Note: ${ }^{*} p<0.05$ 
TABLE IV. THE RESULTS OF ANOVA UNDER SELF-INTEREST ATTRIBUTION

\begin{tabular}{|c|l|c|c|c|}
\hline Test variable & \multicolumn{1}{|c|}{ Frame } & $\mathrm{N}$ & Mean value & F-test \\
\hline \multirow{2}{*}{$\begin{array}{c}\text { Green } \\
\text { consumption } \\
\text { behavior } \\
\text { intention }\end{array}$} & Loss framing & 24 & 3.4722 & \multirow{2}{*}{$3.333^{*}$} \\
\cline { 2 - 4 } & Gain framing & 26 & 3.5000 & \\
\cline { 2 - 4 } & Frameless & 26 & 2.6795 & \\
\hline
\end{tabular}

Note: ${ }^{*} p<0.05$

\section{CONClusion AND PROSPECT}

\section{A. Conclusion and Management Implications}

In the past, the researches on the effect of information frame on consumer decision-making were mostly conducted from the perspective of adjusting and matching. However, this study explains the effect process from the perspective of attribution theory, using the method of scenario experiment and the information frame. Firstly, this study indicates that the use of information frame can promote consumers' green consumption behaviors more than non-use of information frame. Secondly, compared with the gain frame, the loss frame can be a better incentive to promote consumers' green consumption behaviors. Thirdly, when the altruistic attribution is stronger, consumers' green consumer behaviors can be better promoted. Fourthly, when the altruistic attribution is stronger, the loss frame can promote consumers' green consumer behaviors more than the gain frame. However, when the self-interest attribution is stronger, it will weaken the promotion of the loss frame. As a result, there is no significant difference between the loss frame and the gain frame, and neither of the two frames can promote consumers' green consumption behaviors.

In the managerial practice, companies should use the correct language strategy to effectively communicate green consumer service information to consumers. Besides, green consumer services can be described by using a loss frame that emphasizes that failing to do something can lead to certain consequences. At the same time, as the supporters and participants of hotels' green consumer service, hotels should pay more attention to the motivation attribution of consumers.
Nowadays, with the overflow of green marketing, some enterprises use the cover of "green environmental protection" in order to seek higher profits, making consumers question the veracity of green. Therefore, hotels should make consumers believe that the original intention of corporates to promote green consumption behaviors is good and try to avoid the selfinterest attribution.

\section{B. Limitations and Prospects}

The limitations of this study are as follows: firstly, the test participants of this study are college students. So, whether the test can be applied by other ages and education groups is yet to be further verified. Secondly, this study selects only the scenario of reducing the laundering sheets and quilt covers. Thirdly, the green consumer behavior is also a form of prosocial behavior, and the behavior intention may be disturbed by the surrounding environment. In the future, the field experiment can be utilized.

\section{REFERENCES}

[1] A. Tversky, D. Kahneman, "The framing of decisions and the psychology of choice,” vol. 211. Science, 1981, pp. 453-458.

[2] Levin, Schneider, Gaeth, "All frames are not created equal: a typology and critical analysis of framing effects,” vol. 76. Organizational behavior and human decisionprocesses, 1998, pp. 149-188.

[3] C. Chang, Y. Lee, "Effects of message framing,vividness congruency and statistical framing on responses to charity advertising," vol. 29. Inter national Journal of Advertising, 2010, pp. 195-220.

[4] Dongjin Li, Jianxin Liu, Yapei Zhang, Jun Zhen, "The influence of advertising information framework on consumers' purchase intention of virtual products: Based on the mediating role of perceived scarcity," vol. 11. Journal of Marketing Science, 2015, pp. 30-47.

[5] F. Heider, The Psychology of Interpersonal Relations. New York: Wiley, 1958.

[6] L.A. Mohr, D.J. Webb, "The effects of corporate social responsibility and price on consumer responses," vol. 39. Journal of Consumer Affairs, 2005, pp. 121-147.

[7] Yan Kou. "The impact of corporate social responsibility behavior on consumers' response: the role of consumer expectation and perceived motivation,"Southwestern University of Finance and Economics, 2009.

[8] Wenjun Hao. "The influence of corporate social responsibility perception on consumers' purchase intention under egoistic attribution.," Jilin University, 2017. 